\title{
PROPRIEDADES FÍSICAS DO SOLO E PRODUTIVIDADE DE ARROZ IRRIGADO EM DIFERENTES SISTEMAS DE MANEJO(1)
}

\author{
Amauri Nelson Beutler ${ }^{(2)}$, Janete Denardi Munareto ${ }^{(3)}$, Cleiton José Ramão ${ }^{(3)}$, Leandro \\ Galon $^{(4)}$, Naimã Pinto Dias ${ }^{(3)}$, Bruna Canabarro Pozzebon ${ }^{(3)}$, Lucas Antônio Telles \\ Rodrigues $^{(3)}$, Gerisson Souza Munareto ${ }^{(3)}$, Robson Giacomeli ${ }^{(3)}$ \& Priscila Vogelei $\operatorname{Ramos}^{(3)}$
}

\begin{abstract}
RESUMO
O Estado do Rio Grande do Sul é o maior produtor de arroz irrigado do País, com destaque para a região da Fronteira Oeste. $O$ objetivo deste trabalho foi avaliar propriedades físicas do solo e a produtividade de arroz irrigado por inundação em plantio direto e convencional, em níveis de palha residual de arroz em plantio direto. $O$ delineamento experimental foi inteiramente casualizado, com quatro experimentos e 10 repetições nos experimentos 1,2 e 3 e seis no experimento 4 . Os sistemas de manejo foram: experimento 1 (E1), sistema PD (E1PD) e sistema convencional com duas gradagens na camada de 0-7 cm + remaplan (E1C), em área de um ano de cultivo de arroz, após sete anos de pousio do cultivo de arroz e semeadura de azevém no inverno, com pastejo animal o ano todo; experimento 2 (E2), sistema PD (E2PD) e sistema convencional (E2C), após campo nativo; experimento 3 (E3), sistema PD (E3PD) e sistema convencional (E3C), após plantio direto de arroz irrigado durante dois anos em área de campo nativo; e no experimento 4 utilizaram-se quatro níveis de palha residual antes da semeadura do arroz. A produtividade de arroz irrigado por inundação não diferiu entre os sistemas plantio direto e convencional. A massa seca residual do arroz antes da semeadura não influenciou a produtividade de arroz irrigado por inundação.
\end{abstract}

Termos de indexação: restos culturais, plantio direto, rendimento, Oryza sativa.

(1) Recebido para publicação em 11 de outubro de 2011 e aprovado em 06 de agosto de 2012.

(2) Professor Adjunto III, Universidade Federal do Pampa - UNIPAMPA, Campus Itaqui. Rua Luiz Joaquim de Sá Brito, s/n. CEP 97650-000 Itaqui (RS). E-mail: amaurib@yahoo.com.br

(3) Aluno (a) do curso de Agronomia, UNIPAMPA, Campus Itaqui. E-mails: jdmunaret@gmail.com, cleitonramão1@yahoo.com.br, naymã.dias@gmail.com, bru_pozzebon07@hotmail.com, lucasatr2009@hotmail.com robsongiacomeli@unipampa.edu.br, pv_ramos89@hotmail.com

(4) Professor Adjunto II, Universidade Federal Fronteira Sul - UFFS, Campus Erechim. Av. Dom João Hoffmann, 313. CEP 99700-000 Erechim (RS). E-mail: leandro.galon@uffs.edu.br 


\title{
SUMMARY: SOIL PHYSICAL PROPERTIES AND RICE STRAW LEVELS IN MANAGEMENT SYSTEMS: EFFECTONIRRIGATED RICE YIELD
}

\begin{abstract}
The State of Rio Grande do Sul is the greatest producer of flooded rice of Brazil, concentrated mostly along the western border. The objective was to evaluate soil physical properties and flooded rice yield in no-till and conventional tillage systems and rice straw levels in no-till system. The study consisted of four experiments (E), laid out in experimental design was completely randomized blocks, with four experiments $(E)$ and 10 repetitions in experiment 1, 2 and 3 and 6 in experiment 4. The management system in E1 consisted of no-till (E1PD) and conventional tillage with two harrowings (layer 0.0-0.07) $m$ after levelling (E1C), on soil where rice had been gown for one year followed by seven years of fallow, with rye grass sowing in the winter and grazing all year long; E2: no-till (E2PD) and conventional tillage (E2C), after native grassland; E3: no-till (E3PD) and conventional tillage (E3C) after notillage rice for two years on a native grassland area; E4: four rice straw levels had been used before rice sowing. The yield of flooded rice did not differ between no-till and conventional tillage. The residual dry mass of rice before sowing did not influence the flooded rice yield.
\end{abstract}

Index terms: rice straw, no-till, yield, Oryza sativa.

\section{INTRODUÇÃO}

O arroz, segundo cereal mais cultivado no mundo, é um dos cereais mais importantes na alimentação humana, com papel estratégico em relação à segurança alimentar. No Brasil, o Estado do Rio Grande do Sul produz 61 \% dos grãos de arroz, sendo este cultivado no sistema irrigado por inundação, o qual apresenta elevada produtividade comparada à do arroz de sequeiro. A região da fronteira oeste do RS, com destaque para os municípios de Uruguaiana e Itaqui, é a maior produtora dessa commoditie e responsável pelas maiores produtividades de arroz no Estado (Sosbai, 2010).

O preparo do solo tem início logo após a colheita do arroz, nos meses de fevereiro a março, e normalmente compreende uma aração, duas gradagens e aplainamento com remaplan, seguido do entaipamento (Embrapa, 2005). O preparo do solo antecipado visa preparar a superfície do solo para receber as sementes de arroz e, principalmente, estimular a germinação e emergência de sementes de plantas daninhas, como as de arroz-vermelho e preto, num período em que estas não possam concorrer com a cultura do arroz. Antes da semeadura é realizada apenas a dessecação das plantas invasoras (Embrapa, 2005). O revolvimento do solo é realizado para preparar o solo, incorporar e acelerar a decomposição da palha residual do arroz, considerada prejudicial quando em excesso. Para solos de várzea, 2 a $3 \mathrm{t} \mathrm{ha}^{-1}$ de massa seca são suficientes para que se tenha adequada cobertura para implantação do plantio direto. Quantidades maiores, além de dificultarem a evaporação da água do solo, podem produzir ácidos orgânicos em níveis tóxicos ao arroz (Embrapa, 2005), resultando em menor germinação, menor crescimento radicular e menor peso e altura de plântulas (Sousa \& Bortolon, 2002). Em níveis elevados de ácidos orgânicos, a toxidez pode causar menor absorção de nutrientes pelas plantas
(Camargo et al., 2001; Schmidt et al., 2007), entre estes, N, P, K, Ca e Mg (Sousa \& Bortolon, 2002), e menor produtividade do arroz irrigado (Camargo et al., 1995).

Os principais ácidos orgânicos produzidos pela decomposição anaeróbia da matéria orgânica, em solos alagados, são o fórmico, o acético, o propiônico e o butírico, que ocorrem geralmente na concentração de 0,1 a $14 \mathrm{mmol} \mathrm{L}^{-1}$ (Camargo et al., 2001), sendo as maiores concentrações quando há maior quantidade de palha, e o ácido acético, liberado em maiores quantidades e nas primeiras semanas após a inundação (Angeles et al., 2005). Quantidades de palha de arroz acima de 6,5 t ha-1 causam redução da produção de arroz em vasos (Camargo et al., 1995).

Segundo Johnson et al. (2006), em sistema plantio direto (PD), em que os restos culturais do arroz permanecem na superfície do solo, ocorre maior concentração de ácidos orgânicos, que podem limitar a produtividade quando em níveis excessivos. Entretanto, são escassos os estudos sobre o efeito de níveis residuais de palha de arroz na produtividade de arroz irrigado, o que leva os produtores a realizaram em inúmeras operações de preparo para acelerar a decomposição da palha, com vistas à sua redução e mitigação dos possíveis efeitos nocivos na produtividade - relatados pelos produtores e ainda pouco conhecidos e quantificados.

O sistema PD reduz a degradação do solo, principalmente por minimizar a erosão hídrica deste, devido à ausência de revolvimento e à contínua deposição e manutenção de resíduos vegetais em superfície. Contudo, alterações estruturais ocorrem nos solos cultivados sob esse sistema. Solos sob plantio direto têm apresentado problemas de compactação subsuperficial (Pedrotti et al., 2001; Reinert et al., 2008). Além disso, quando se utiliza o pastoreio animal durante o inverno pode haver alteração estrutural do solo, observada pela compactação das camadas 
superficiais e comprometimento da sua qualidade física, sobretudo se realizado com solo úmido e com elevadas taxas de lotação animal (Lanzanova et al., 2007). A qualidade estrutural do solo está relacionada à umidade, à dinâmica de nutrientes no solo e à produtividade das plantas (Carter, 2002).

$\mathrm{O}$ sistema PD consiste no não revolvimento do solo e resulta na diminuição dos custos de produção, permitindo o uso mais eficiente das máquinas agrícolas e o plantio das culturas na época recomendada. Isso é importante, uma vez que a época de semeadura ideal é de poucas semanas e muitas vezes ocorrem intensas precipitações nesses períodos, diminuindo drasticamente a quantidade de dias ótimos disponíveis para semeadura do arroz, com ênfase nos solos de várzea, amplamente utilizados para o cultivo de arroz e que têm drenagem lenta da água.

O objetivo deste trabalho foi avaliar atributos físicos do solo e níveis de palha de arroz residual na produtividade de arroz irrigado por inundação em sistemas de manejo de preparo convencional e plantio direto.

\section{MATERIAL E MÉTODOS}

Os experimentos foram realizados nas coordenadas de $29^{\circ} 40^{\prime} 55^{\prime \prime} \mathrm{S}$ e $56^{\circ} 38^{\prime} 17^{\prime \prime} \mathrm{W}$, em Uruguaiana, RS, em altitude de 85 m, em Neossolo Litólico (Embrapa, 2006) com $4 \%$ de declividade média. O clima é do tipo $\mathrm{Cfa}$, segundo Köppen-Geiger.

O delineamento experimental foi inteiramente casualizado, com quatro experimentos e dez repetições nos experimentos 1,2 e 3 e seis repetições no experimento 4 (parcelas de $3 \times 2 \mathrm{~m}$ ). Nos experimentos 1,2 e 3 , os sistemas de manejo foram: experimento 1 (E1), sistema plantio direto (E1PD) e preparo convencional com duas gradagens na camada de 0-7 $\mathrm{cm}+$ aplainamento com remaplan (E1C), em área de um ano de cultivo de arroz e passagem de rolo-faca após a colheita, após sete anos de pousio do cultivo de arroz e semeadura de azevém no inverno, com pastejo animal o ano todo; experimento 2 (E2), sistema plantio direto (E2PD) e preparo convencional (E2C), após campo nativo; e experimento 3 (E3), sistema plantio direto (E3PD) e preparo convencional (E3C), após plantio direto de arroz irrigado durante dois anos em área de campo nativo.

Para avaliar melhor os efeitos da palha na superfície do solo sobre a produtividade do arroz irrigado, foi conduzido o E4, visto que na região é realizado preparo anual do solo para incorporar e acelerar a decomposição da palha residual do arroz, visando reduzir os possíveis efeitos supressivos sobre a produtividade do arroz irrigado por inundação, pouco conhecidos e quantificados.

O experimento 4 foi instalado ao lado do experimento 3 , com as mesmas características de solo e manejo, sendo estabelecidas quatro quantidades de palha residual de arroz, antes da semeadura da cultura em plantio direto: ausência de palha (0); palha residual atual (8.196); duas vezes (16.392); e três vezes (24.588 $\left.\mathrm{kg} \mathrm{ha}^{-1}\right)$ a quantidade de palha sobre a superfície do solo. No inverno, as áreas ficaram em pousio e a soca do arroz utilizada para pastoreio com lotação animal inferior a 1,2 unidade animal por hectare.

A composição granulométrica, na camada de 0-20 $\mathrm{cm}$, determinada pelo método da pipeta (Claessen, 1997), foi de: 215,605 e $180 \mathrm{~g} \mathrm{~kg}^{-1}$, no E1; 271,577 e $152 \mathrm{~g} \mathrm{~kg}^{-1}$, no E2; e 342, 467 e $191 \mathrm{~g} \mathrm{~kg}^{-1}$ de argila, silte e areia, no E3 e E4. A composição química do solo é apresentada no quadro 1.

Em agosto, foi preparado o solo no sistema convencional, sendo construídas e remontadas as taipas no sistema plantio direto, com camalhão de 0,12 $\mathrm{m}$ de altura e dimensionamento entre taipas suficiente para permitir uma lâmina de água de $+0,04 \mathrm{~m}$ de altura sobre o solo, a qual foi aplicada 20 dias após a emergência do arroz.

Antes da semeadura, foram aplicados herbicidas e foi avaliada a quantidade de massa seca na superfície do solo, em área de $0,25 \mathrm{~m}^{2}$ por repetição.

A semeadura foi realizada na primeira semana do mês de outubro em todos os experimentos, na densidade de 60 sementes por metro linear e no espaçamento de 0,17 m entre linhas. Utilizou-se a variedade Irga 424 nos experimentos 1, 3 e 4 e BR - Irga 409 no experimento 2. A adubação foi de $240 \mathrm{~kg} \mathrm{ha}^{-1}$ de 0920-30 de N-P-K, na semeadura; $150 \mathrm{~kg} \mathrm{ha}^{-1}$ de 36-0012 N-P-K 20 dias após a semeadura, antes da entrada da água; $60 \mathrm{~kg} \mathrm{ha}^{-1}$ de 36-00-12 N-P-K no perfilhamento; e $60 \mathrm{~kg} \mathrm{ha}^{-1}$ de $45-00-00 \mathrm{~N}-\mathrm{P}-\mathrm{K}$ na diferenciação do primórdio floral.

Após a semeadura, foram determinadas a densidade do solo (Ds), porosidade total, macro e microporosidade em amostras indeformadas coletadas com cilindros de $5 \mathrm{~cm}$ de diâmetro e $3 \mathrm{~cm}$ de altura, nas camadas de 0-5 e 5-10 cm, de acordo com Claessen (1997).

No florescimento, foram avaliados a massa seca em $2 \mathrm{~m}$ lineares e o teor de $\mathrm{N}$ na parte aérea, segundo Tedesco et al. (1995). Na colheita, foram avaliados o número de panículas e a produtividade de grãos de arroz com $12 \%$ de umidade, em área de $2 \mathrm{~m}^{2}$.

Quadro 1. Caracterização química do solo, nos experimentos, antes da semeadura do arroz

\begin{tabular}{|c|c|c|c|c|c|c|c|}
\hline Expe & $\mathbf{p H}$ & MO & $\mathbf{C a}$ & Mg & K $\mathbf{P}$ & P-Mehlich & h V \\
\hline & $\mathrm{H}_{2} \mathrm{O}$ & $\%$ & $-c$ & ${ }_{1}{ }_{c}$ & & $\mathrm{mg} \mathrm{dm}{ }^{-3}$ & $\%$ \\
\hline $\mathrm{E} 1$ & 4,9 & 2,5 & 7,9 & 2,7 & 0,164 & 3,7 & 61,0 \\
\hline $\mathrm{E} 2$ & 51 & 6,1 & 13,7 & 6,5 & 0,716 & 16,2 & 77,1 \\
\hline $\mathrm{E} 3$ e $\mathrm{E} 4$ & 4,9 & 3,4 & 12,1 & 5,6 & 0,205 & 3,0 & 76,4 \\
\hline
\end{tabular}


Os resultados foram submetidos à análise de variância; quando significativa, foi aplicado o teste de Tukey a $5 \%$, para comparação das médias em cada experimento.

\section{RESULTADOS E DISCUSSÃO}

A densidade do solo (Ds) foi inferior no sistema convencional, comparado ao sistema plantio direto (PD), na camada de 0,0-0,05 m, nos experimentos $2 \mathrm{e}$ 3 , em razão do revolvimento com as gradagens, que resultou em maior porosidade total no sistema convencional (Quadro 2). Na camada de 0,05-0,10 m, essas diferenças foram menores, e apenas no experimento 3 a Ds foi superior no sistema PD, porém a porosidade total foi superior no sistema convencional, sendo alterada apenas a relação macro/microporos. Segundo Bertol et al. (2004), o preparo do solo é a atividade que atua diretamente na estrutura do solo; no sistema convencional, as alterações são mais pronunciadas, em relação à Ds e porosidade.

No E2, a Ds foi inferior no primeiro ano de cultivo sobre campo nativo, comparado ao E1, em que o solo estava sendo utilizado para cultivo e pastoreio animal há vários anos. Esses resultados corroboram o de Lima et al. (2008), que verificaram aumento da Ds e alterações estruturais no solo decorrentes do cultivo, comparado ao campo nativo, em Planossolo. Isso demonstra que o cultivo de arroz irrigado promove alterações estruturais e compactação gradual do solo, conforme também verificado por Pedrotti et al. (2001) e Munareto et al. (2010). Pedrotti et al. (2001) verificaram, em Planossolos de textura média, que ocorreu maior Ds quando cultivado com arroz irrigado, com arações e gradagens, e maior na camada de 0,10 $0,20 \mathrm{~m}$, atribuída à ação contínua dos implementos agrícolas durante o preparo convencional do solo e ao tráfego das máquinas agrícolas. Entretanto, os valores de Ds são considerados baixos e não limitantes à produtividade, para solos de textura média, em relação aos valores registrados como restritivos em experimentos com culturas de sequeiro (Beutler \& Centurion, 2004; Collares et al., 2006; Reinert et al., 2008), sugerindo que a Ds não foi fator limitante à produtividade de arroz. Reinert et al. (2008) verificaram que, em solo de textura média, houve redução do crescimento das plantas a partir da Ds de $1,75 \mathrm{Mg} \mathrm{m}^{-3}$.

Além disso, no cultivo do arroz irrigado é realizado o alagamento do solo no início do desenvolvimento das plantas de arroz, no estádio V3/V4, de três a quatro

Quadro 2. Densidade do solo, macroporosidade, microporosidade e porosidade total, em três experimentos e nas profundidades de 0,0-0,05 e 0,05-0,10 m, em sistemas de manejo

\begin{tabular}{|c|c|c|c|c|}
\hline \multirow{2}{*}{ Tratamento } & \multirow{2}{*}{ Densidade do solo } & \multicolumn{3}{|c|}{ Porosidade } \\
\hline & & Macro & Micro & Total \\
\hline & $\mathrm{Mg} \mathrm{m}^{-3}$ & & $\mathrm{~m}^{3} \mathrm{~m}^{-3}$ & \\
\hline & \multicolumn{4}{|c|}{$0,0-0,05 \mathrm{~m}$} \\
\hline E1PD & $1,27 \mathrm{a}$ & $0,11 \mathrm{a}$ & $0,37 \mathrm{a}$ & $0,48 \mathrm{z}$ \\
\hline E1C & $1,16 \mathrm{a}$ & $0,15 \mathrm{a}$ & $0,28 \mathrm{~b}$ & $0,43 \mathrm{a}$ \\
\hline $\mathrm{E} 2 \mathrm{PD}$ & $1,05 \mathrm{a}$ & $0,10 \mathrm{a}$ & $0,44 \mathrm{~b}$ & $0,54 \mathrm{~b}$ \\
\hline $\mathrm{E} 2 \mathrm{C}$ & $0,83 \mathrm{~b}$ & $0,08 \mathrm{a}$ & $0,51 \mathrm{a}$ & $0,59 \mathrm{a}$ \\
\hline E3PD & $1,28 \mathrm{a}$ & $0,06 \mathrm{~b}$ & $0,41 \mathrm{~b}$ & $0,47 \mathrm{~b}$ \\
\hline \multirow[t]{2}{*}{$\mathrm{E} 3 \mathrm{C}$} & $1,01 \mathrm{~b}$ & $0,14 \mathrm{a}$ & $0,44 \mathrm{a}$ & $0,58 \mathrm{a}$ \\
\hline & \multicolumn{4}{|c|}{$0,05-0,10 \mathrm{~m}$} \\
\hline E1PD & $1,27 \mathrm{~b}$ & $0,10 \mathrm{a}$ & $0,35 \mathrm{a}$ & $0,45 \mathrm{a}$ \\
\hline $\mathrm{E} 1 \mathrm{C}$ & $1,48 \mathrm{a}$ & $0,07 \mathrm{~b}$ & $0,36 \mathrm{a}$ & $0,43 \mathrm{~b}$ \\
\hline E2PD & $1,11 \mathrm{a}$ & $0,10 \mathrm{~b}$ & $0,41 \mathrm{a}$ & $0,51 \mathrm{~b}$ \\
\hline $\mathrm{E} 2 \mathrm{C}$ & $1,12 \mathrm{a}$ & 0,15 a & $0,39 \mathrm{a}$ & $0,54 \mathrm{a}$ \\
\hline E3PD & $1,34 \mathrm{a}$ & $0,06 \mathrm{~b}$ & $0,41 \mathrm{a}$ & $0,47 \mathrm{~b}$ \\
\hline E3C & $1,18 \mathrm{~b}$ & $0,16 \mathrm{a}$ & $0,39 \mathrm{a}$ & $0,55 \mathrm{a}$ \\
\hline
\end{tabular}

Médias seguidas de letras iguais, na mesma camada de solo e no mesmo experimento, não diferem entre si pelo teste de Tukey a $5 \%$. Experimento 1 (E1), sistema plantio direto (E1PD) e sistema convencional com duas gradagens na profundidade de 0-7 cm + remaplan (E1C), em área de um ano de cultivo de arroz e passagem de rolo-faca após a colheita, após sete anos de pousio do cultivo de arroz e semeadura de azevém no inverno, com pastejo animal o ano todo; experimento 2 (E2), sistema plantio direto (E2PD) e sistema convencional (E2C), após campo nativo; e experimento 3 (E3), sistema plantio direto (E3PD) e sistema convencional (E3C), após plantio direto de arroz irrigado durante dois anos em área de campo nativo. 
folhas, quando as plantas estão com o sistema radicular superficial (Sosbai, 2010). A partir do alagamento, começa o perfilhamento e aprofundamento do sistema radicular das plantas condição em que a compactação do solo tem menos influência no crescimento radicular, pois diminui a resistência à penetração das raízes no solo com o aumento da umidade. $\mathrm{O}$ decréscimo do efeito negativo da Ds com o aumento da sua umidade, que diminui a resistência à penetração das raízes no solo, foi discutido por Brady \& Weil (2008) e verificado em Assis et al. (2009). Dessa forma, o efeito da compactação do solo em decorrência do sistema PD é menos expressivo no desenvolvimento do arroz irrigado, visto que nessa condição o solo apresenta consistência semifluida, baixa coesão entre as partículas e menor resistência à deformação e penetração das raízes, considerando que para o crescimento radicular é necessário o deslocamento de partículas de solo pelas raízes (Brady \& Weil, 2008). Além disso, os efeitos da compactação também são menores para a cultura do arroz irrigado, pois este possui aerênquimas e não depende da aeração do solo para seu desenvolvimento, a qual é reduzida pelo decréscimo dos macroporos, como consequência da compactação. Essas propriedades explicam a produtividade de arroz que não diferiu entre os sistemas de manejo (Quadro 3), mesmo com variação da densidade e porosidade do solo no sistema de preparo convencional, comparado ao PD.

A massa seca, o teor de N na parte aérea do arroz, o número de panículas e a produtividade do arroz irrigado por inundação não diferiram entre o preparo convencional e o sistema PD (Quadro 3). Também em um Neossolo, Munareto et al. (2010) constataram, em um dos experimentos, que a produtividade de arroz irrigado foi 8,2\% superior no sistema convencional com gradagens, comparado ao sistema PD, com 5.659 $\mathrm{kg} \mathrm{ha}^{-1}$ de massa seca residual na superfície do solo antes da semeadura. Já em menores quantidades de palha na superfície, não foram verificadas diferenças na produtividade de arroz. Esses autores inferem que a menor produção no sistema PD com maior quantidade de massa seca residual de arroz pode ser consequência do efeito supressivo da palha, devido aos ácidos orgânicos de cadeia curta, tóxicos, produzidos por microrganismos anaeróbios, e em maior concentração no sistema PD, conforme verificado por Bohnen et al. (2005) e Johnson et al. (2006).

Bohnen et al. (2005), estudando a concentração de ácidos orgânicos produzidos pela palha de azevém após o alagamento, verificaram maior concentração do ácido acético, com pico de produção no quinto dia após o alagamento; as diferenças entre os sistemas PD e convencional perduraram apenas até o décimo primeiro dia após o alagamento, quando a produção dos três ácidos orgânicos já estava reduzida, próximo a $10 \%$ dos valores máximos atingidos no quinto dia após alagamento. Além do efeito tóxico, os ácidos orgânicos podem ainda causar redução na absorção de nutrientes pelas plantas de arroz, conforme verificado por Sousa \& Bortolon (2002) e Schmidt et al. (2007).

Nesse contexto, no E3, com massa seca na superfície do solo de $8.196 \mathrm{~kg} \mathrm{ha}^{-1}$ não foi verificada

Quadro 3. Massa seca (MS) na superfície do solo antes da semeadura e produtividade de arroz irrigado por inundação nos experimentos 1, 2 e 3, comparando os sistemas plantio direto (PD) e convencional (C)

\begin{tabular}{|c|c|c|c|c|c|}
\hline \multirow{2}{*}{ Tratamento } & \multicolumn{2}{|c|}{ Massa seca } & \multirow{2}{*}{$\mathrm{N}$ na parte aérea } & \multirow{2}{*}{ Número de panículas } & \multirow{2}{*}{ Produtividade } \\
\hline & Superficie do solo & Parte aérea & & & \\
\hline & \multicolumn{2}{|c|}{ - $\mathrm{kg} \mathrm{ha}^{-1}$} & $\%$ & $\mathrm{~m}^{2}$ & $\mathrm{~kg} \mathrm{ha} \mathrm{h}^{-1}$ \\
\hline & & & Experiment & & \\
\hline E1PD & 4.323 & $13.596 \mathrm{a}$ & $2,47 \mathrm{a}$ & $447 \mathrm{a}$ & $8.345 \mathrm{a}$ \\
\hline \multirow[t]{2}{*}{ E1C } & - & $14.729 \mathrm{a}$ & $2,43 \mathrm{a}$ & 465 a & $8.427 \mathrm{a}$ \\
\hline & \multicolumn{4}{|c|}{ Experimento 2} & \\
\hline E2PD & 2.932 & $15.975 \mathrm{a}$ & $3,03 \mathrm{a}$ & $491 \mathrm{a}$ & $8.045 \mathrm{a}$ \\
\hline \multirow[t]{2}{*}{$\mathrm{E} 2 \mathrm{C}$} & - & $17.552 \mathrm{a}$ & $3,19 \mathrm{a}$ & $487 \mathrm{a}$ & 8.169 a \\
\hline & \multicolumn{4}{|c|}{ Experimento 3} & \\
\hline E3PD & 8.196 & $13.760 \mathrm{a}$ & $2,85 \mathrm{a}$ & 612 a & $9.592 \mathrm{a}$ \\
\hline E3C & - & 13.889 a & $2,92 \mathrm{a}$ & $652 \mathrm{a}$ & $10.276 \mathrm{a}$ \\
\hline
\end{tabular}


redução na produtividade de arroz irrigado no sistema PD em relação ao convencional; essa quantidade de palha foi bem superior à utilizada por Munareto et al. (2010).

No E4, a produtividade de arroz não diferiu entre os tratamentos com níveis de palha residual na superfície do solo de 0 a $24.588 \mathrm{~kg} \mathrm{ha}^{-1}$, antes da semeadura (Quadro 4), cujo valor máximo utilizado no experimento dificilmente é atingido em condições de cultivo de arroz irrigado no campo, considerando a produção de massa seca (Quadro 3) e sua decomposição anual. Isso permite inferir que a palha residual de arroz na superfície do solo, no sistema $\mathrm{PD}$, não reduziu a produtividade de arroz irrigado por inundação, conforme relatado em outros estudos com palha de arroz (Camargo et al., 1995; Munaretto et al., 2010). Camargo et al. (2001), em revisão de literatura, relataram os efeitos nocivos de ácidos orgânicos voláteis, quando em excesso, na absorção de nutrientes, perfilhamento, produção de massa seca, número de panículas, esterilidade de flores e produtividade do arroz. Camargo et al. (1995) verificaram que quantidade excessiva de palha de arroz, acima de 6,5 t ha ${ }^{-1}$, triturada e incorporada a um Gleissolo, em vasos, reduziu a produtividade de arroz. Contudo, até 20 t ha $^{-1}$, ocorreu pouca redução na produtividade, na condição de vasos em que a água ficou estagnada na superfície do solo. Nesse contexto, deve-se considerar que em cultivos de arroz em lavouras comerciais condição em que este trabalho foi executado normalmente há circulação de água nos talhões, diluindo o efeito dos ácidos orgânicos produzidos, em função do carreamento e dispersão destes pelo fluxo de superfície, a exemplo do que ocorre com os nutrientes, conforme verificado por Swarowsky et al. (2004, 2006). Estes autores constataram que, quando não houve fluxo de água e esta permaneceu estagnada na superfície, houve redução de $12 \%$ da produtividade do arroz irrigado.

Assim, a mesma produtividade de arroz, no E4, nos tratamentos com até $24.588 \mathrm{~kg} \mathrm{ha}^{-1}$ de palha de

Quadro 4. Quantidade de massa seca (MS) de arroz na superfície do solo antes da semeadura e produtividade de arroz irrigado por inundação, em plantio direto, no experimento 4

MS na superfície do solo Produtividade de arroz

\begin{tabular}{cr}
\hline & \\
\hline & $\mathrm{kg} \mathrm{ha}^{-1}$ \\
& $10.483 \mathrm{a}$ \\
16.392 & $9.628 \mathrm{a}$ \\
24.588 & $9.688 \mathrm{a}$ \\
\end{tabular}

Médias seguidas da mesma letra minúscula, na coluna, não diferem entre si pelo teste de Tukey $(p<0,05)$. arroz em superfície, possivelmente, ocorreu em razão da declividade da área de $4 \%$, a qual permitiu fluxo da água na superfície do solo, diluindo e dispersando os ácidos orgânicos e seus efeitos, que são produzidos em condições de alagamento.

Estudos com restos culturais de arroz no campo são escassos, porém Menezes et al. (2001) observaram decréscimo da produtividade de genótipos de arroz irrigado em sistema PDo sobre palha de azevém, de 9,4 e 8,8 \% em dois anos; em um ano, não houve diferença de produtividade, comparado à área em pousio no inverno, atribuindo-se esse efeito à produção de substâncias tóxicas pela palha de azevém, dessecado apenas 15 dias antes da semeadura. Já Vieira (2010) não verificou redução na produtividade de arroz quando cultivado após azevém com massa seca de 4,42 t ha-1, dessecado 34 dias antes da semeadura, comparado ao pousio, e que a solução do solo apresentou aos 23 dias após o alagamento apenas ácido acético na forma dissociada, não tóxica ao arroz.

Esses resultados permitem inferir que a produtividade do arroz irrigado em sistemas de manejo, cultivado em sistema PD no campo após restos culturais de arroz, na média dos quatro experimentos e mais dois experimentos apresentados em Munareto et al. (2010), não é reduzida por causa da quantidade de palha e do sistema de manejo.

\section{CONCLUSÕES}

1. A variação da densidade e porosidade do solo em decorrência do manejo não altera a produtividade de arroz irrigado por inundação.

2. A produtividade de arroz irrigado por inundação não difere entre os sistemas plantio direto e convencional.

3. A massa seca residual do arroz antes da semeadura não influencia a produtividade de arroz irrigado por inundação.

\section{AGRADECIMENTOS}

Ao Técnico Agrícola da Fazenda Fonte Rica, Geri Munareto, pela cessão da área e pelo auxílio na execução dos experimentos. Ao CNPq, pela concessão das bolsas ao primeiro e segundo autores.

\section{LITERATURA CITADA}

ASSIS, R.L.; LAZARINI, G.D.; LANÇAS, K.P. \& CARGNELUTTI FILHO, A. Avaliação da resistência do solo à penetração em diferentes solos com a variação do teor de água. Eng. Agríc., 29:558-568, 2009. 
ANGELES, O.R.; JOHNSON, S.E. \& BURESH, R.J. Soil solution sampling for organic acids in rice paddy soils. Soil Sci. Soc. Am. J., 70:48 70, 2005.

BERTOL, I.; ALBUQUERQUE, J.A.; LEITE, D.; AMARAL, A.J. \& ZOLDAN JUNIOR, W.A. Propriedades físicas do solo sob preparo convencional e semeadura direta em rotação e sucessão de culturas, comparadas às do campo nativo. R. Bras. Ci. Solo, 25:155-163, 2004.

BEUTLER, A.N. \& CENTURION, J.F. Compactação do solo no desenvolvimento radicular e na produtividade de soja. Pesq. Agropec. Bras., 39:581-588, 2004.

BOHNEN, H.; SILVA, L.S.; MACEDO, V.R.M. \& MARCOLIN, E. Ácidos orgânicos na solução de um Gleissolo sob diferentes sistemas de cultivo com arroz irrigado. R. Bras. Ci. Solo, 29:475-480, 2005.

BRADY, N.C. \& WEIL, R.R. The nature and properties of soils. 14.ed. New Jersey, Pearson Prentice Hall, 2008. 975p.

CAMARGO, F.A.O.; ZONTA, E.; SANTOS, G.A. \& ROSSIELLO, R.O.P. Aspectos fisiológicos e caracterização da toxidez de ácidos orgânicos voláteis em plantas. Ci. Rural, 31:523 529, 2001.

CAMARGO, F.A.O.; SANTOS, G.A.; ROSSIELLO, R.O.P. \& ZONTA, E. Incorporação de palha de arroz em um Gleissolo e efeitos no rendimento da cultura do arroz irrigado. Pesq. Agropec. Bras., 30:983 987, 1995.

CARTER, M.R. Soil quality for sustainable land management: Organic matter and aggregation interactions that maintain soil functions. Agron. J., 94:38-47, 2002.

CLAESSEN, M.E.C., org. Manual de métodos de análise de solo. 2.ed. Rio de Janeiro, Embrapa - CNPS, 1997. 212p.

COLLARES, G.L.; REINERT, D.J.; REICHERT, J.M. \& KAISER, D.R. Qualidade física do solo na produtividade da cultura do feijoeiro num Argissolo. Pesq. Agropec. Bras., 41:1663-1674, 2006.

EMPRESA BRASILEIRA DE PESQUISA AGROPECUÁRIA EMBRAPA. Cultivo do arroz irrigado no Brasil. 2005. Disponível em: <http://sistemasdeproducao.cnptia. embrapa.br/FontesHTML/Arroz/ArrozIrrigadoBrasil>. Acesso em: 21 de jun. de 2010.

EMPRESA BRASILEIRA DE PESQUISA AGROPECUÁRIA EMBRAPA. Sistema brasileiro de classificação de solos. Rio de Janeiro, Ministério da Agricultura e do Abastecimento, 2006. 306p.

JOHNSON, S.E.; ANGELES, O.R.; BRAR, D.S. \& BURESH, R.J. Faster anaerobic decomposition of a brittle straw rice mutant: implications for residue management. Soil Biol. Biochem., 38:1880-1892, 2006.

LANZANOVA, M.E.; NICOLOSO, R.S.; LOVATO, T.; ELTZ, F.L.F.; AMADO, T.J.C. \& REINERT, D.J. Atributos físicos do solo em sistema de integração lavoura-pecuária sob plantio direto. R. Bras. Ci. Solo, 31:1131-1140, 2007.
LIMA, C.L.R.; PILLON, C.N.; SUZUKI, L.E.A.S. \& CRUZ, L.E.C. Atributos físicos de um Planossolo Háplico sob sistemas de manejo comparados aos do campo nativo. R. Bras. Ci. Solo, 32:1849-1855, 2008.

MENEZES, V.G.; MARIOT, C.H.P.; LOPES, M.C.B.; SILVA, P.R.F. \& TEICHMANN, L.L. Semeadura direta de genótipos de arroz irrigado em sucessão a espécies de cobertura de inverno. Pesq. Agropec. Bras., 36:1107-1115, 2001.

MUNARETO, J.D.; BEUTLER, A.N.; RAMÃO, C.J.; DIAS, N.P.; RAMOS, P.V.; POZZEBON, B.C.; ALBERTO, C.M. \& HERNANDES, G.C. Propriedades físicas do solo e produtividade de arroz irrigado por inundação no sistema plantio direto. Pesq. Agropec. Bras., 45:14991506, 2010.

PEDROTTI, A.; PAULETTO, E.A.; GOMES, A.S.; TURATTI, A.L. \& CRESTANA, S. Sistemas de cultivo de arroz irrigado e a compactação de um Planossolo. Pesq. Agropec. Bras., 36:709-715, 2001.

REINERT, D.J.; ALBUQUERQUE, J.A.; REICHERT, J.M.; AITA, C. \& ANDRADA, M.M.C. Limites críticos de densidade do solo para o crescimento de raízes de plantas de cobertura em Argissolo Vermelho. R. Bras. Ci. Solo, $32: 1805-1816,2008$.

SCHMIDT, F.; BORTOLON, L. \& SOUZA, R.O. Toxidez pelos ácidos propiônico e butírico em plântulas de arroz. Ci. Rural, 37:720-726, 2007.

SOCIEDADE SUL-BRASILEIRA DE ARROZ IRRIGADO SOSBAI. Arroz irrigado: Recomendações técnicas da pesquisa para o Sul do Brasil. Porto Alegre, 2010. $188 \mathrm{p}$.

SOUSA, R.O. \& BORTOLON, L. Crescimento radicular e da parte aérea do arroz (Oryza sativa L.) e absorção de nutrientes, em solução nutritiva com diferentes concentrações de ácido acético. R. Bras. Agroci., 8:231$235,2002$.

SWAROWSKY, A.; RIGHES, A.A.; MARCHEZAN, E.; RHODEN, A.C. \& GUBIANI, E.I. Manejo da palha de azevém, da adubação de base e da água de drenagem na produção de arroz irrigado. Ci. Rural, 34:393-397, 2004.

SWAROWSKY, A.; RIGHES, A.A.; MARCHEZAN, E.; RHODEN, A.C. \& GUBIANI, E.I. Concentração de nutrientes na solução do solo sob diferentes manejos do arroz irrigado. R. Bras. Eng. Agr. Amb., 10:344-351, 2006.

TEDESCO, M.J.; GIANELLO, C.; BISSANI, C.A.; BOHNEN, H. \& VOLKWEISS, S.J. Análise de solos, plantas e outros materiais. Porto Alegre, Universidade Federal do Rio Grande do Sul, 1995. 174p.

VIEIRA, V.M. Manejo da adubação nitrogenada no arroz irrigado em sucessão ao azevém. Porto Alegre, Universidade Federal do Rio Grande do Sul, 2010. (Tese de Mestrado) 